\title{
Success Factors for Agile Software Development - A Case Study from Sri Lanka
}

\author{
V. N. Vithana \\ Department of IT \\ SLIIT \\ Sri Lanka
}

\author{
S. G. S. Fernando \\ Department of IT \\ SLIIT \\ Sri Lanka
}

\author{
M. Kapurubandara \\ Department of IT \\ SLIIT \\ Sri Lanka
}

\begin{abstract}
Agile software development methods provide great flexibility to adapt to changing requirements and rapidly market products. Sri Lankan software organizations too are embracing these methods to develop software products. Being an iterative an incremental software engineering methodology, agile philosophy promotes working software over comprehensive documentation and heavily relies on continuous customer collaboration throughout the life cycle of the product. Hence characteristics of the people involved with the project and their working environment plays an important role in the success of an agile project compared to any other software engineering methodology. This study investigated the factors that lead to the success of a project that adopts agile methodology in Sri Lanka. An online questionnaire was used to collect data to identify people and organizational factors that lead to project success. The sample consisted of Sri Lankan software professionals with several years of industry experience in developing projects using agile methods. According to the statistical data analysis, customer satisfaction, customer commitment, team size, corporate culture, technical competency, decision time, customer commitment and training and learning have a influence on the success of the project.
\end{abstract}

\section{General Terms}

Agile software development methods.

\section{Keywords}

Success factors, agile software development methods.

\section{INTRODUCTION}

Software development methods constantly evolve due to new technologies and demands of the users. Organizations need to continuously adapt new structures, strategies and policies to stay competitive in today's dynamic business environment. Thus, agile software development methods are becoming increasingly popular with the great flexibility they provide organizations to adapt to changing requirements and to market products rapidly.

Agile software development (ASD) methods were originated by a group of 17 software practitioners in the year 2001. ASD principles were based on best practices of these software practitioners and their previous success and failure experiences with many past software projects [1].

ASD philosophy constitutes of a set of principles where there is more value on Individuals and interactions over processes and tools; Working software over comprehensive documentation; Customer collaboration over contract negotiation; Responding to change over following a plan [1].

On the contrary, traditional development methods are more focused on following well defined plans and are inflexible in a rapidly changing business environment. Thus, when traditional methods are used, software practitioners get so involved with the process and consequently the real development gets slowed down.

Today, agile philosophy seems to have inspired many software practitioners all over the world as it has a huge impact on how the software is being developed. Under the umbrella 'Agile' there are several development methodologies such as Scrum, XP, Kanban, Crystal, to name a few. Agile methodologies such as XP and Scrum are in widespread use in developed countries such as US, Europe and Japan [2].

Nowadays most of the software development is carried out offshore in cost effective developing countries such as India and Sri Lanka [3]. According to Fowler, Offshore development brings two issues which conflict with the principles of agile development. Firstly, ASD methods highly stress the importance of having face-to face communication. But in offshore development, developers are not residing in the same physical proximity which creates a barrier for faceface communication. Secondly, most offshore organizations favor the plan-driven approach where detailed requirements or designs are sent offshore to be constructed. But ASD methods value working software over comprehensive documentation and are willing to change at customer's request over following a rigid plan. Therefore offshore developers might not be comfortable with the flexibility that ASD methods offer. The characteristics of the people involved with the project and the culture plays an important role in the success of an agile project. According to the literature, effective communication, readiness to learn, negotiation skills, autonomy to take rapid decision are some of the key determinants of an agile project success.

Most software offshore outsourcing destinations are now established in Sri Lanka and these Sri Lankan companies are too adopting ASD methods to a considerable extent. There are few studies carried out on identifying the success factors in adopting ASD methods in the western, developed countries. There is very little empirical studies from Asian countries [4]. It would be interesting to study whether these factors are similar in the Sri Lankan context where the personal characteristics and culture are vastly different from the developed, western countries.

Therefore, this research try to address the following research question.

"What are the factors from the perspective of ASD practitioners that will influence the success of projects that want to adopt ASD methods in Sri Lanka?"

Software professionals who are interested in adopting ASD methods, would be interested to know the factors on which his team should focus that would lead to the success of the project. 
It is believed that the findings of this paper would become useful to those who wish to adopt ASD methods and for researchers in software industry.

The rest of the paper is organized as follows: the Literature Review identifies factors that affect the success of an agile project and explains how to determine the success of a project. Methodology discusses the research methodology that was followed to conduct the research while an analysis of statistical data is provided under Results and Discussion. The paper concludes providing some directions for future research.

\section{LITERATURE REVIEW}

There are several factors that contribute to the success of a project. From a project management perspective, a successful project should meet the original targeted cost, schedule, quality, and functionality by the efficient use of resources. A quality product should be in confirmation with the requirements specification and also fit for use [5]. Nowadays, a successful project is defined using four factors as follows. A successful project 1) meets business requirements, 2) delivered and maintained on schedule, 3) delivered and maintained within budget and 4) deliver the expected business value and return on investment [6]. Hence, in this research, project success which is the dependent variable is measured using the following criteria 1)Reduced delivery schedules, 2) Increased return on investment (ROI), 3) Increased ability to meet with the current customer requirements, 4) Increased flexibility to meet with the changing customer requirements, 5) Improved business processes.

This section briefly reviews the literature to identify the factors that influence the success of a software project that adopt agile methods.

\subsection{Factors influencing the adoption of Agile Methods in Software Development}

According to the literature, customer plays a very important role in the success of an agile software project. Customer involvement in the project can be categorised as customer collaboration, customer satisfaction and customer commitment. Agile manifesto sees customer collaboration as one of the main requirements in project success. Lindvall et all states that continuous customer collaboration throughout the life cycle of the project is a critical success factor of an Agile project [7]. One of the agile principles is to give the highest priority to the customer through early and continuous delivery of valuable software [1]. According to a study conducted by Misra et al customer satisfaction followed by customer collaboration are considered to be the most important factors in determining a project success [8]. Since ASD methods are Incremental and iterative, customer is an important stake holder throughout the life cycle of the project. Customer plays a very responsible role in the project by verifying the software and prioritizing requirements at each iteration. Hence customer commitment is also an important success factor [9].

Agile teams are said to be self-organizing and hence do not rely on outsiders to guide them. The team has the autonomy to organize themselves to best complete their work [10]. Agile teams need to take quick decisions by themselves [11]. Therefore decision making time is a key factor in agile project success.

The geographical location of the team members play an important role in software development. When the team members are located in different areas worldwide, they will be working in different cultures and different time zones which in return would become a barrier for effective communication. As Cockburn states distant communication over a phone will miss out important information including gestures and facial expressions. Also the stakeholders might limit the conversations and assume things that would not happen in a face-to face conversation. Hence distant communication would lead to miscommunication of important information [12]. Therefore geographical distribution of the team members is considered as an important factor in agile software project success.

When the team size is small, effective communication could be easily achieved [8]. But when the team size expand beyond 20-40 members, face-to face communication becomes very difficult [7]. Therefore many argue that team size play a key role in agile project success.

Agile manifesto emphasizes the importance of Individual and interactions over processes and tools. An agile project needs a highly corporative environment to be successful. Agile projects highly rely on customer collaboration and continuous feedback. Hence the organization should be dynamic and highly flexible to change. Close collaboration among team members is also required. The organization culture should support negotiation [11]. Agile methods would be successful in a friendly and collaborative work environment and hence would be difficult to be implemented in a bureaucratic organization culture [13]. Therefore organization culture plays an important role in implementing agile methods.

Traditional software methods rely on documented plans but agile methods prefer internal planning and control within the team rather than interference from external managers. Therefore the level of autonomy on planning and control is an important success factor [10]; [12].

Any software projects' success depend on the people and human resource factor. ASD methods rely on the people factor more than any other methodology. The people factor is categorised into several sub factors in the literature such technical competency, personal characteristics, communication and negotiation, societal culture and training and learning of team members [8], [9].

Competency denotes whether the team member possess past experience in developing similar software and is equipped with good interpersonal and communication skills [7]. According to Lindvall et al about $25 \%$ of the project personal need to be competent for the project to be successful. A highly competent team would deliver quality software fast. Since ASD methods emphasizes on delivering working software fast, certainly, competency plays an important role in the project success.

Agile teams possess more autonomy in taking decisions. Therefore personal characteristics of the team members such as honesty, collaborative attitude, sense of responsibility and readiness to learn are considered important in driving an agile project towards success [7], [13].

ASD methods heavily rely on face to face communication over written documentation [13]. Therefore effective communication and negotiation is a necessity of an agile project success [9], [12].

According to Misra et al software development is influenced by the local culture of the society in which the organization operates. Personal characteristics of the people are greatly influenced by the society and vice versa. It would be easier to 
implement agile methods in a societal culture that promotes effective communication, motivation for progress and flexibility among individuals [7], [8].

Lindvall et al states that explicit training is trivial for the success of an agile project. ASD methods such as XP requires less formal training as transferring of tacit knowledge and mentoring is achieved through pair programming.

The above literature survey on the influencing factors reveal that there are many significant success factors which affect the adoption of Agile Methodologies in software projects.
These factors can be grouped to develop a framework for investigations. This paper proposes the following framework for this purpose. The success factors for the adoption of agile methodologies can be broadly categorised into 5 categories. They are namely Organizational, people, process, technical and project [9]. This research considers only People and Organizational categories as out of the five, these two categories might have the highest variance in the Asian context. Figure 1 summarises the success factors that were identified in the People and Organizational categories adopted from [8].

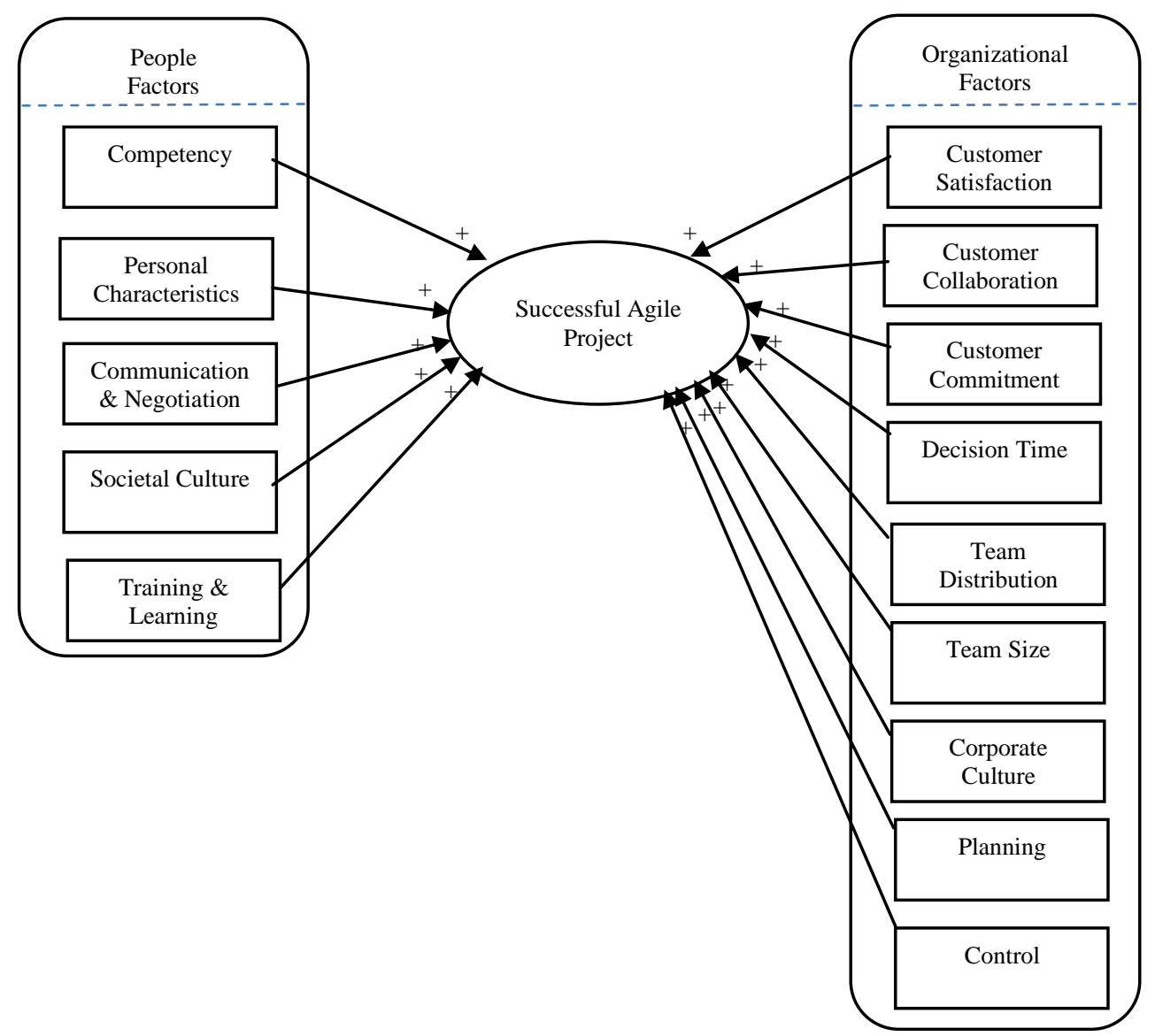

Fig 1: Theoretical framework - Success Factors (adapted from [8])

\section{RESEARCH METHODOLOGY}

This research is investigating the success factors to adoption of Agile Software Development methods in the software companies in Sri Lanka. The purpose of this study is to come up with a set of potential determinates that influence the success of the adoption.

\section{The goal of this study is to}

- Extend the understanding and find empirical evidence of the success factors

- Determine the significance of the potential success factors which impacts the adoption.

\subsection{Research Approach}

Given the lack of empirical research in this area especially in Sri Lanka, an exploratory investigation was considered the most suitable approach. Sri Lanka, a developing country, with many offshore and as well as local software companies are established, is the chosen test bed. A methodology suitable for
Sri Lanka could prove to be useful with other developing countries with a similar cultural background.

This research try to identify the success factors from the perspective of the software professionals. Hence the criterion for selection of software professionals was their number of years of experience in the industry. Software practitioners playing different job roles (i.e. software engineer, project manager) working in various industries and possess more than 3 years of experience using ASD methods in different types of projects were selected. The study deployed a questionnaire and the questionnaire link was emailed to selected software practitioners. The questionnaire was sent in September 2014 and kept open for 3 months to collect responses. The extensive literature review, contributed to the design of the proposed research model and the survey instrument.

\subsection{Survey Instrument}

Questionnaire was the main instrument of this study and was designed after going through a few similar research studies conducted in developed countries. This method was cost 
effective and the respondents could take their time to answer the questions thoughtfully. A survey instrument with questions using Likert scales was developed and pilot tested to capture the information, reflections and perceptions of the software professionals. It was designed to investigate the success factors that influence adoption of agile technology by the organizations and their significance.

The questionnaire mainly consisted of close-ended, multiple choice type questions. It consisted of a few open-ended questions which provided the opportunity for the respondent to give some additional information. The survey had three sections. The first section of the survey included of questions to gather demographic data about the respondent. The second section had questions to identify the success factors of agile development. To measure importance of success factors, a 5point Likert scale was used to reflect the level of perception of the question by the respondent. The third section was used to identify respondent's perspective on the success of a software project.

Several pilot tests were carried out prior to the distribution of the questionnaire. Pilot tests were conducted with a group of 2 software quality assurance engineers, 2 software engineers, and 1 project manager.

Overall, 170 questionnaires were personally disseminated and addressed to software practitioners with no constraints on the type of industry sectors.

A covering letter was sent along with the questionnaire link explaining the purposes of the study, assuring anonymity of respondents and their organization, and providing instructions on how and who should complete the questionnaire. The recipients were selected using a random systematic sampling technique from Sri Lankan agile groups in social media such as LinkedIn and Facebook. Follow-up efforts to nonrespondents were made through emailing again after two weeks. Out of 78 total responses, 14 were incomplete, resulting in 64 usable responses, that is, a $37 \%$ response rate from the 170 delivered questionnaires. This sample size is considered adequate for the analysis and is comparable to response rates in literature [Sekaran \& Bougie, 2010].

\section{DATA ANALYSIS}

The data were statistically analyzed using SPSS.

78 responses were received from which 64 were filtered based on the completeness and the number of years of experience in using ASD methods. The responses considered are those with 2 or more years of experience in the industry developing projects using ASD methods.

Demographic data about the respondents were collected. Most of the companies (36\%) that responded to our survey are having 50 to 250 employees. $25 \%$ of the respondents came from large organizations, having more than 500 employees. $23 \%$ of the respondents are from small companies with less than 50 employees. Thus, the sample consists of a fair distribution from small, medium and large organizations.

$47 \%$ of the respondents have 5 to 10 members in their teams. $16 \%$ are in teams which have less than 5 members. $23 \%$ are having 11 to 20 members. $13 \%$ are having more than 20 members. 63\% belong to small sized groups (have less than 10 members). Thus, the sample consists of a fair distribution of small (less than 10) and large teams.

Out of the respondents $28 \%$ are software engineers, $25 \%$ are Team leaders and $19 \%$ are Quality Assurance engineers. The rest of the respondents consists of project managers, consultants, business analysts, UI engineers and project coordinators.

Out of the respondents $52 \%$ are serving only the foreign client base and $33 \%$ are serving both foreign and local clients. $77 \%$ of the respondents are using Scrum methodology. $9 \%$ of the respondents are using XP and another $9 \%$ are using Lean methodology respectively. Other respondents are practicing ASD, Crystal and USDP.

$29 \%$ of the respondents are having 2 years of experience using agile methodologies. 55\% are having 3 years of experience. $10 \%$ are having 4 years of experience and $6 \%$ are having more than 5 years of experience.

\subsection{Descriptive Statistics}

The descriptive statistics of the data collected from respondents were studied and summarized in Table 1. For each independent variable Mean, Mode, Minimum, Maximum and Standard Deviation was calculated.

Table 1 - Summarized Descriptive Statistics

\begin{tabular}{lcccc}
\hline Independent Variable & Mean & $\begin{array}{c}\text { M } \\
\text { od }\end{array}$ & $\begin{array}{c}\text { Mode } \\
\text { \% }\end{array}$ & $\begin{array}{c}\text { Standard } \\
\text { Deviation }\end{array}$ \\
\hline Customer Satisfaction & 4.78 & 5 & $77 \%$ & .417 \\
Customer Collaboration & 3.92 & 4 & $45 \%$ & 1.044 \\
Customer Commitment & 4.17 & 4 & $41 \%$ & .747 \\
Decision Time & 4.19 & 4 & $42 \%$ & .852 \\
Team Distribution & 3.30 & 5 & $33 \%$ & 1.391 \\
Team Size & 4.56 & 5 & $61 \%$ & .732 \\
Corporate Culture & 4.25 & 5 & $53 \%$ & .561 \\
Planning & 3.62 & 4 & $28 \%$ & 1.054 \\
Control & 4.00 & 4 & $45 \%$ & .756 \\
Technical Competency & 4.27 & 4 & $47 \%$ & .740 \\
Personal Characteristics & 4.35 & 5 & $50 \%$ & .728 \\
Communication and & 3.54 & 4 & $42 \%$ & .700 \\
Negotiation & & & & .930 \\
\hline Societal Culture & 3.60 & 4 & $36 \%$ & 1.109 \\
Training and Learning & 4.16 & 5 & $41 \%$ & .930 \\
\hline
\end{tabular}

According to the descriptive statics, following people factors have a mean value above 4

- Personal Characteristics

- Technical Competency

- Training and Learning

According to the descriptive statics, following people factors have a mean value above 4 .

- Customer Satisfaction

- $\quad$ Team Size

- Corporate Culture 
- Decision Time

- Customer Commitment

\subsection{Factor Analysis}

Respondents were asked to indicate their agreement with statements by circling a number of the Likert scale ( $1=$ strongly disagree to $5=$ strongly agree). Data for some factors were collected through several questions. Thus, factors analysis was conducted for the factors, team distribution, corporate culture, personal characteristcs, communication and negotiation and societal culture.

\section{Cooperate Culture (CC)}

In this construct there are eight items, each item is measured on a Likert scale of 1 to 5 where the response of 1 indicates Strongly Disagree while response of 5 indicates Strongly Agree to the statement. The descriptive statistics and the inter item correlation values are given in table 1. Principle axis functioning has been used in factor analysis.

Table 2 : Descriptive Statistics Summery and Inter Correlation for items in CC

\begin{tabular}{|c|c|c|c|c|c|c|c|c|c|c|}
\hline \multirow{2}{*}{ Item } & \multicolumn{2}{|c|}{ Descriptive Summery } & \multicolumn{8}{|c|}{ Inter - Item correlation } \\
\hline & Mean & Std. Deviation & $\mathrm{CC} 1$ & $\mathrm{CC} 2$ & $\mathrm{CC} 3$ & $\mathrm{CC} 4$ & CC5 & CC6 & $\mathrm{CC} 7$ & $\mathrm{CC} 8$ \\
\hline $\mathrm{CC} 1$ & 4.51 & .669 & 1.000 & .588 & .419 & .256 & .319 & .145 & .041 & .286 \\
\hline $\mathrm{CC} 2$ & 4.54 & .563 & .588 & 1.000 & .647 & .176 & .396 & .092 & .244 & .302 \\
\hline $\mathrm{CC} 3$ & 4.46 & .591 & .419 & .647 & 1.000 & .075 & .353 & .133 & .189 & .135 \\
\hline $\mathrm{CC} 4$ & 4.27 & .787 & .256 & .176 & .075 & 1.000 & .391 & .482 & .287 & .218 \\
\hline CC5 & 4.25 & .822 & .319 & .396 & .353 & .391 & 1.000 & .366 & .033 & .513 \\
\hline CC6 & 3.57 & 1.118 & .145 & .092 & .133 & .482 & .366 & 1.000 & .163 & .373 \\
\hline $\mathrm{CC} 7$ & 3.81 & 1.229 & .041 & .244 & .189 & .287 & .033 & .163 & 1.000 & .231 \\
\hline $\mathrm{CC} 8$ & 4.06 & .840 & .286 & .302 & .135 & .218 & .513 & .373 & .231 & 1.000 \\
\hline
\end{tabular}

Based on the mean values in table 2, there seems to agreement in all 4 as somewhat Agree on Cooperate Culture. The highest correlation for each item with at least one other item in the construct is between 0.3 and 0.9, except for CC7. Hence CC7 was dropped and Factor analysis has been conducted again. In Kaiser-Meyer-Olkin (KMO) value is 0.668 , which is considered to be acceptable. Single factors were extracted that explained $50 \%$ of the variance in the four items (which is exactly $50 \%$ ). The smallest factor loading is 0.5 [19]. The mean of seven was computed and saved as CC to be used in further Analysis.

\section{Team Distribution (TD)}

In this construct there are eight items, each item is measured on a Likert scale of 1 to 5 where the response of 1 Strongly Disagree while response of 5 indicates Strongly Agree to the statement. The descriptive statistics and the inter item correlation values are given in table 2. Principle axis functioning has been used in factor analysis.

Table 3 : Descriptive Statistics Summery and Inter Correlation for items in TD

\begin{tabular}{|c|c|c|c|c|}
\hline \multirow[b]{2}{*}{ Item } & \multicolumn{2}{|c|}{ Descriptive Summery } & \multicolumn{2}{|c|}{ Inter - Item correlation } \\
\hline & Mean & $\begin{array}{c}\text { Std. } \\
\text { Deviation }\end{array}$ & TD1 & TD2 \\
\hline TD1 & 3.55 & 1.391 & 1.000 & .469 \\
\hline TD2 & 3.05 & 1.419 & .469 & 1.000 \\
\hline
\end{tabular}

Based on the mean values in table 3, there seems to agreement in all 3 as Neither Disagree nor Agree on Team Distribution. The highest correlation for each item with at least one other item in the construct is between 0.3 and 0.9 . Hence both items correlate adequately in the construct. In Kaiser-Meyer-Olkin (KMO) value is 0.5 , which is considered to be mediocre. Single factors were extracted that explained $49.8 \%$ of the variance in the two items (which is almost 50\%). The smallest factor loading is 0.5 [19]. The mean of two was computed and saved as TD to be used in further Analysis.

\section{Personal Characteristics (PC)}

In this construct there are six items, each item is measured on a Likert scale of 1 to 5 where the response of 1 indicates Strongly Disagree while response of 5 indicates Strongly Agree to the statement. The descriptive statistics and the inter item correlation values are given in table 3. Principle axis functioning has been used in factor analysis. 
Table 4 : Descriptive Statistics Summery and Inter Correlation for items in PC

\begin{tabular}{|c|c|c|c|c|c|c|c|c|}
\hline \multirow{2}{*}{ Item } & \multicolumn{2}{|c|}{ Descriptive Summery } & \multicolumn{3}{|c|}{ Inter - Item correlation } & \multirow[b]{2}{*}{$\mathrm{PC} 4$} & \multirow[b]{2}{*}{ PC5 } & \multirow[b]{2}{*}{ PC6 } \\
\hline & Mean & Std. Deviation & $\mathrm{PC} 1$ & $\mathrm{PC} 2$ & PC3 & & & \\
\hline $\mathrm{PC} 1$ & 4.26 & .651 & 1.000 & .540 & .727 & .666 & .679 & .605 \\
\hline PC2 & 4.42 & .666 & .540 & 1.000 & .585 & .589 & .579 & .590 \\
\hline PC3 & 4.37 & .730 & .727 & .585 & 1.000 & .805 & .748 & .611 \\
\hline $\mathrm{PC} 4$ & 4.37 & .683 & .666 & .589 & .805 & 1.000 & .762 & .792 \\
\hline PC5 & 4.42 & .641 & .679 & .579 & .748 & .762 & 1.000 & .724 \\
\hline PC6 & 4.40 & .689 & .605 & .590 & .611 & .792 & .724 & 1.000 \\
\hline
\end{tabular}

Based on the mean values in table 4 , there seems to agreement in all 4 as Somewhat Agree on personal characteristics. The highest correlation for each item with at least one other item in the construct is between 0.3 and 0.9 . Hence six items correlate adequately in the construct. In Kaiser-Meyer-Olkin (KMO) value is 0.866 , which is considered to be good. Single factors were extracted that explained $67 \%$ of the variance in the four items (which is more than 50\%). The smallest factor loading is 0.68 [19]. The mean of six was computed and saved as $\mathrm{PC}$ to be used in further Analysis.

\section{Communication and Negotiation $(\mathrm{CN})$}

In this construct there are five items, each item is measured on a Likert scale of 1 to 5 where the response of 1 indicates Strongly Disagree while response of 5 indicates Strongly Agree to the statement. The descriptive statistics and the inter item correlation values are given in table 5. Principle axis functioning has been used in factor analysis.

Table 5 : Descriptive Statistics Summery and Inter Correlation for items in CN

\begin{tabular}{|c|c|c|c|c|c|c|c|}
\hline \multirow{2}{*}{ Item } & \multicolumn{2}{|c|}{ Descriptive Summery } & \multicolumn{3}{|c|}{ Inter - Item correlation } & \multirow[b]{2}{*}{$\mathrm{CN} 4$} & \multirow[b]{2}{*}{ CN5 } \\
\hline & Mean & Std. Deviation & $\mathrm{CN} 1$ & $\mathrm{CN} 2$ & $\mathrm{CN} 3$ & & \\
\hline $\mathrm{CN} 1$ & 4.27 & .700 & 1.000 & .245 & -.011 & -.060 & .197 \\
\hline $\mathrm{CN} 2$ & 3.71 & 1.211 & .245 & 1.000 & .500 & .464 & .346 \\
\hline $\mathrm{CN} 3$ & 3.10 & 1.353 & -.011 & .500 & 1.000 & .654 & .183 \\
\hline $\mathrm{CN} 4$ & 2.92 & 1.395 & -.060 & .464 & .654 & 1.000 & .269 \\
\hline CN5 & 4.05 & .958 & .197 & .346 & .183 & .269 & 1.000 \\
\hline
\end{tabular}

Based on the mean values in table $4, \mathrm{CN} 1$ and $\mathrm{CN} 5$ have a mean value above 4 which indicates Somewhat Agree in the likert scale. In the questionnaire, $\mathrm{CN} 1$ was 'Our projects have mechanisms that enable personnel to communicate and negotiate quickly and effectively with developers, operations, support, customers, management, and business areas'. CN5 was 'Most people in our projects are amicable to each other to such an extent that they communicate with each other with trust and good will'. A mean value above 4 indicates the majority agrees with $\mathrm{CN} 1$, and $\mathrm{CN} 5$. $\mathrm{CN} 3$ and $\mathrm{Cn} 4$ are having relatively low mean values indicating Somewhat Disagree in the Likert scale. In the questionnaire, CN3 was 'In most cases, communication and negotiation in our projects happen between people who are physically close to one another'. CN4 was 'In most cases, communication and negotiation in our projects happen between people who work in the same (similar) time zone as ours'. Hence majority of the respondents state that they do not communicate with people in the same physical proximity or same time zone. From the respondents $52 \%$ are serving only the foreign clients. Thus it is not possible to communicate in the same physical proximity or same time zone.

The highest correlation for each item with at least one other item in the construct is between 0.3 and 0.9 except for CN1. Hence CN1 is dropped and analysis is conducted again. In Kaiser-Meyer-Olkin (KMO) value is 0.68 , which is considered to be acceptable. Single factors were extracted that explained $50 \%$ of the variance in the four items (which is exactly $50 \%$ ). The smallest factor loading is 0.65 [19]. The mean of four was computed and saved as $\mathrm{CN}$ to be used in further Analysis.

\section{Socialite Culture}

In this construct there are four items, each item is measured on a Likert scale of 1 to 5 where the response of 1 indicates Strongly Disagree while response of 5 indicates Strongly Agree to the statement. The descriptive statistics and the inter item correlation values are given in table 6. Principle axis 
functioning has been used in factor analysis.

Based on the mean values in table 6 , there seems to agreement in all 3 as Neither disagree nor agree. The highest correlation for each item with at least one other item in the construct is between 0.3 and 0.9 . Hence all four items correlate adequately in the construct. In Kaiser-Meyer-Olkin (KMO) value is 0.737 , which is considered to be good. Single factors were extracted that explained $60 \%$ of the variance in the two items (which is almost 50\%). The smallest factor loading is 0.539 [19]. The mean of four was computed and saved as SC to be used in further Analysis.

Table 6 : Descriptive Statistics Summery and Inter Correlation for items in SC

\begin{tabular}{|c|c|c|c|c|c|c|}
\hline \multirow{2}{*}{ Item } & \multicolumn{2}{|c|}{$\begin{array}{c}\text { Descriptive } \\
\text { Summery }\end{array}$} & \multicolumn{4}{|c|}{ Inter - Item correlation } \\
\cline { 2 - 7 } & Mean & $\begin{array}{c}\text { Std. } \\
\text { Deviatio } \\
\mathrm{n}\end{array}$ & $\mathrm{SC} 1$ & $\mathrm{SC} 2$ & $\mathrm{SC} 3$ & $\mathrm{SC} 4$ \\
\hline
\end{tabular}

\begin{tabular}{|l|r|r|r|r|r|r|}
\hline $\begin{array}{l}\text { SC } \\
1\end{array}$ & 3.61 & .953 & 1.000 & .617 & .637 & .483 \\
\hline $\begin{array}{l}\text { SC } \\
2\end{array}$ & 3.50 & 1.039 & .617 & 1.000 & .846 & .475 \\
\hline $\begin{array}{l}\text { SC } \\
3\end{array}$ & 3.55 & 1.038 & .637 & .846 & 1.000 & .417 \\
\hline $\begin{array}{l}\text { SC } \\
4\end{array}$ & 3.77 & 1.109 & .483 & .475 & .417 & 1.000 \\
\hline
\end{tabular}

\section{Success}

In this construct there are five items, each item is measured on a Likert scale of 1 to 5 where the respondents of 1 indicates Strongly Disagree while response of 5 indicates Strongly Agree to the statement. The descriptive statistics and the inter item correlation values are given in table 7 . Principle axis functioning has been used in factor analysis.

Table 7 : Descriptive Statistics Summery and Inter Correlation for items in SC

\begin{tabular}{|c|c|c|c|c|c|c|c|}
\hline \multirow{2}{*}{ Item } & \multicolumn{2}{|c|}{$\begin{array}{l}\text { Descriptive } \\
\text { Summery }\end{array}$} & \multicolumn{5}{|c|}{ Inter - Item correlation } \\
\hline & Mean & $\begin{array}{c}\text { Std. } \\
\text { Deviati } \\
\text { on }\end{array}$ & $\begin{array}{l}\text { DeliverySc } \\
\text { hedule }\end{array}$ & IncreasedROI & meetCustReq & $\begin{array}{c}\text { meetChangingC } \\
\text { ustReq }\end{array}$ & $\begin{array}{c}\text { businessProce } \\
\text { ss }\end{array}$ \\
\hline DeliverySchedule & 3.94 & 1.097 & 1.000 & .600 & .521 & .366 & .473 \\
\hline IncreasedROI & 3.92 & 1.103 & .600 & 1.000 & .382 & .305 & .269 \\
\hline meetCustReq & 4.30 & .810 & .521 & .382 & 1.000 & .695 & .730 \\
\hline $\begin{array}{l}\text { meetChangingCust } \\
\text { Req }\end{array}$ & 4.25 & .909 & .366 & .305 & .695 & 1.000 & .776 \\
\hline businessProcess & 4.31 & .833 & .473 & .269 & .730 & .776 & 1.000 \\
\hline
\end{tabular}

Based on the mean values in table 7 , there seems to agreement in all 4 as somewhat agree on Success. The highest correlation for each item with at least one other item in the construct is between 0.3 and 0.9 . Hence all five items correlate adequately in the construct. In Kaiser-Meyer-Olkin (KMO) value is 0.744 , which is considered to be good. Single factors were extracted that explained $69 \%$ of the variance in the two items (which is almost 50\%). The smallest factor loading is 0.524 [19]. The mean of five was computed and saved as SC to be used in further Analysis.

\section{People factors}

This research considers technical competency, personal characteristics, communication and negotiation, societal culture and training and learning as the people factors.

Based on the Pearson's Correlation Analysis, there is a correlation between project success and technical competency $(0.518>0.3)$. In multiple linear regression analysis the $\mathrm{P}$ value is less than 0.05 . Thus, technical competency can be used to predict Success. The results indicate that the other factors do not have a correlation.
Table 8 : Summarised correlations table for people factors

\begin{tabular}{|l|r|r|}
\hline \multicolumn{1}{|c|}{ Factors } & $\begin{array}{c}\text { Correlatio } \\
\mathrm{n}\end{array}$ & $\begin{array}{c}\text { P } \\
\text { Value(Regres } \\
\text { sion } \\
\text { Analysis) }\end{array}$ \\
\hline $\begin{array}{l}\text { Success and Technical } \\
\text { Competency }\end{array}$ & 0.518 & .000 \\
$\begin{array}{l}\text { Success and Personal } \\
\text { Characteristics }\end{array}$ & 0.164 & .783 \\
$\begin{array}{l}\text { Success and Communication } \\
\text { and Negotiation }\end{array}$ & 0.045 & .971 \\
Success and Societal Culture & 0.148 & .405 \\
Success and Training Learning & 0.124 & .441 \\
\hline
\end{tabular}


Table 9 : Summarized correlations table for organizational factors

\begin{tabular}{|l|r|r|}
\hline \multicolumn{1}{|c|}{ Factors } & Correlation & \multicolumn{2}{|c|}{$\begin{array}{c}\text { P } \\
\text { Value(Regressi } \\
\text { on Analysis) }\end{array}$} \\
\hline $\begin{array}{l}\text { Success and Customer } \\
\text { Satisfaction }\end{array}$ & 0.334 & .046 \\
$\begin{array}{l}\text { Success and Customer } \\
\text { Collaboration }\end{array}$ & 0.102 & .879 \\
$\begin{array}{l}\text { Success and Customer } \\
\text { Commitment }\end{array}$ & 0.047 & .665 \\
Success and Decision Time & 0.320 & .043 \\
Success and Team Size & 0.402 & .030 \\
Success and Planning & 0.165 & .032 \\
Success and Control & 0.046 & .656 \\
$\begin{array}{l}\text { Success and Team } \\
\text { Distribution }\end{array}$ & 0.333 & .839 \\
$\begin{array}{l}\text { Success and Cooperate } \\
\text { Culture }\end{array}$ & & \\
\hline
\end{tabular}

Organizations Factors

Customer satisfaction, customer collaboration, customer commitment, decision time, team distribution, team size, corporate culture, planning and control are considered as organizational factors.

Based on the Pearson's Correlation Analysis, there is a correlation between Success and Customer Satisfaction (0.334 $>0.3)$, Decision Time $(0.320>0.3)$, Team Size $(0.302>$ $0.3)$,planning $(0.402>0.3)$, Cooperate Culture $(0.333>0.3)$. In multiple linear regression analysis the $\mathrm{P}$ value is less than 0.05 for those factors and they can be used to predict Success. The other factors do not have a correlation.

\section{DISCUSSIONS}

The research question was to identify the factors that affect the success of an ASD project from the perspective of software practitioners.

Based on the Pearson's Correlation Analysis for people factors, technical competency significantly influence agile project success. Based on the literature review this result is justifiable. However, the other people factors namely Personal Characteristics, communication and negotiation, societal culture and training and learning do not significantly influence the success of an agile project. This observation is somewhat surprising according to the existing literature [8], [9]. However most of the previous research is conducted in the developed western countries such as America, Japan and England. In those contexts, the customer is readily available on site. Hence as agile philosophy insists, regular meetings with the customer is possible. From our respondents $52 \%$ are doing offshore development serving only the foreign clients base. In an interview with a senior software professional, it was stated that since an onsite customer is not present, usually few team members are sent offshore to gather requirements. Thus, face to face communication and negotiation cannot be achieved. This justifies the mean value of 3 received for the statements 'In most cases, communication and negotiation in our projects happen between people who are physically close to one another and who work in the same (similar) time zone as ours'.

Based on the Pearson's Correlation Analysis, customer satisfaction, decision time, team size, planning, corporate culture are significantly influencing the success of an agile project. These results are in accordance to the previous literature review. However, customer collaboration, customer commitment, team distribution and control do not have a significant influence on the project success. The reason for this observation might be that the customer is offshore for many Sri Lankan projects. Hence, continuous customer collaboration and commitment seems impossible for projects with offshore customers.

\section{CONCLUSION}

The main objective of this study was to investigate the factors that lead to the success of a software project which adopts agile methods. This study was conducted among Sri Lankan software practitioners to investigate their perspective on the people and organizational factors that affect the project success. An online questionnaire was emailed to software practitioners those who practice ASD methods. The respondents were selected using a random systematic sampling technique from Sri Lankan Agile groups in social media such as LinkedIn and Facebook. Hence the sample consists of practitioners practicing agile techniques from different industry sectors in Sri Lanka. The respondents from small, medium and large size organizations and small to large project teams are included in the sample. Sample consists of different types of job roles such as software Engineer, Quality Assurance Engineers, Team leaders and project managers. The received completed questionnaires were filtered based on the number of years of experience.

The collected data was statistically analyzed using SPSS. According to the respondents view, from the people factors, Technical competency has the highest impact on the success of an agile project. However, the other people factors namely Personal Characteristics, communication and negotiation, societal culture and training and learning do not significantly influence the success of an agile project.

From the organizational factors, customer satisfaction, decision time, team size, planning, corporate culture are significantly influencing the success of an agile project. These results are in accordance to the previous literature review. However, customer collaboration, customer commitment, team distribution and control do not have a significant influence on the project success. The reason for this observation might be that the customer is offshore for many Sri Lankan projects. Thus, continuous customer collaboration and commitment throughout the project lifecycle is impossible with offshore customers.

This study considered only the people and organization factors to study their effect on the project success. Other areas such as the project nature and agile software techniques when considered would provide a holistic view of the factors that affect project success.

Further research is needed to study how agile methods can be adopted in better ways by avoiding the communication barriers that lead to more successful projects. 


\section{ACKNOWLEDGMENTS}

The research team would like to express their sincere gratitude to the Sri Lankan software practitioners who took their valuable time in participating in this study. A special thank you to Ahinsa Vithana and Dilhan Manawadu for the valuable support extended in writing this paper.

\section{REFERENCES}

[1] W. Cunningham, 2001. [Online]. Available: http://www.agilemanifesto.org/.

[2] T. Dyba and T. Dinsoyr, "What do we know about Agile software development," IEEE Software, pp. 6-9, 2009.

[3] M. Fowler, "Using an Agile Software Process with Offshore Development," 2006. [Online]. Available: http://www.martinfowler.com/articles/agileOffshore.html

[4] Inayat, I., Salim, S. S., Marczak, S., Daneva, M., \& Shamshirband, S. (2014). A systematic Literature review on agile requirements engineering practices and challenges. Computers in Human Behavior. doi:10.1016/j.chb.2014.10.046

[5] G. R. Heerkens, Project Management, United States of America: The McGraw-Hill Companies, 2002.

[6] W. R. Duncan, "Defining and Measuring Project Success," $2004 . \quad$ [Online]. Available: http://www.pmpartners.com/resources/defmeas_success. html.

[7] M. Lindvall, V. Basili, B. Boehm, P. Costa, K. Dangle, F. Shull, R. Tesoriero, L. Williams and M. Zelkowitz, "Empirical Findings in Agile Methods," in Proceedings of Extreme Programming and Agile Methods - XP/Agile Universe 2002, 2002.

[8] S. C. Misra, V. Kumar and U. Kumar, "Identifying some important success factors in adopting agile software development practices," The journal of Systems and Software, 2009.

[9] T. Chow and D.-B. Cao, "A survey study of critical success factors in agile software projects," The Journal of Systems and Software, 2008.
[10] K. Schwaber and J. Sutherland, "The Scrum Guide," 2013. [Online]. Available: http://www.scrumguides.org/docs/scrumguide/v1/ScrumGuide-US.pdf\#zoom=100.

[11] M. Fowler, "The New Methodology," 2005. [Online]. Available: http://www.martinfowler.com/articles/newMethodology. html.

[12] A. Cockburn, "Learning From Agile Software Development - Part One," Cross Talk:The Journal of Defense Software Engineering, pp. 10-14, 2002.

[13] S. W. Ambler, "Communication on Agile Software Teams," July 2014. [Online]. Available: http://www.agilemodeling.com/essays/communication.ht $\mathrm{m}$.

[14] P. Abrahmsson, O. Salo and J. Warsta, "Agile Software Development Methods - Review and Analysis," 2002. [Online]. Available: www.vtt.fi/inf/pdf/publications/2002/P478.pdf.

[15] U. Sekaran and R. Bougie, Research Methods for Business-A Skill Building Approach, New Delhi: John Wiley \& Sons, Ltd, 2010.

[16] A. Cockburn, "Learning from agile software development - Part two," CrossTalk:The Journal of Defense Software Engineering, pp. 9-12, 2002.

[17] T. Dyba, "An empirical investigation of the key factors for success in software process improvement," IEEE Transactions on Software Engineering, vol. 31, pp. 410424, 2005.

[18] M. Fowler, "Writing The Agile Manifesto," 2006. [Online]. Available: http://martinfowler.com/articles/agileStory.html.

[19] Hair, J., Black, W., Babin, B., \& Anderson, R. (2010). Multivariate Data Analysis ( Seventh Edition). Upper Saddle River, New Jersey: Prentice Hall 